\title{
Arterial hypertension after age 65: from epidemiology and pathophysiology to therapy. Do we know where we stand?
}

\author{
Jerzy Gąsowski ${ }^{1}$, Karolina Piotrowicz ${ }^{1}$, Franz H. Messerli ${ }^{1,2,3}$ \\ 'Department of Internal Medicine and Gerontology, Faculty of Medicine, Jagiellonian University, Medical College, Krakow, Poland \\ ${ }^{2}$ Division of Cardiology, Mount Sinai Medical Centre, Icahn School of Medicine, New York, United States \\ ${ }^{3}$ Department of Cardiology and Clinical Research, University Hospital, Bern, Switzerland
}

\begin{abstract}
Arterial hypertension is a prevalent disease with great harming potential. After the age of 55 years the remaining lifetime risk of hypertension amounts to $90 \%$. Despite the constant advances some important issues such as the cut-off blood pressure for the initiation of antihypertensive therapy or the therapeutic goal are debated.

In this review, we present - based on the available literature - the current concepts concerning the pathophysiology, epidemiology and antihypertensive therapy in patients aged 65 years or older.

The pathophysiology of hypertension in older patients in principle rests on stiffening of large conduit arteries, which leads to greater systolic and lower diastolic blood pressure. This in most older patients results in isolated systolic hypertension. Additionally most of these patients have low-renin hypertension. Data from large-scale clinical trials indicate that therapy of such individuals with thiazide-like diuretics and long-acting dihydropiridine calcium channel blockers as first-line medications reduces risk of complications. Based on results of recently published trials, meta-analyses, and prospective observations, the optimal on-treatment blood pressure values for most older hypertensive patients should be set within the $130-139 \mathrm{mmHg}$ range. At present, lower values of standard office blood pressure in this group of patients have not been shown to be associated with additional benefits, and may be associated with a greater risk of adverse events.

In conclusion, we recommend that for most patients aged 65 years or more, standard office systolic blood pressure should be cautiously reduced to within 140 and $130 \mathrm{mmHg}$, preferably with a thiazide-like diuretic, long acting dihydropiridine calcium channel blocker or their combination.
\end{abstract}

Key words: older patients, hypertension, isolated systolic hypertension, antihypertensive therapy

Kardiol Pol 2018; 76, 4: 723-730

\section{INTRODUCTION}

Upon reaching the age of 55-60 years, the remaining lifetime risk of becoming hypertensive amounts to $90 \%$ [1, 2]. Arterial hypertension is considered to be one of the leading causes of mortality of older adults, mostly by increasing the risk of such cardiovascular (CV) complications as myocardial infarction, stroke, heart failure or dissection of aortic aneurysms [3-10].

Primary hypertension in older adults is associated with different pathophysiologic background than primary hypertension seen in younger adults. This in large part is related to the ageing process of the CV system and kidneys. The repetitive haemodynamic force exerted during each heart cycle by the contraction of the left ventricle leads to thickening and stiffening of the myocardium, due to accumulation of lipofuscine [11]. The repetitive distensions and recoils of the aorta, which securing the non-zero, appropriate level of diastolic blood pressure (DBP), lead to remodelling of the aorta [12]. In this process, elastine fibres are becoming fragmented, and the amount of collagen increases, along with a change of the prevailing type of collagen [13]. Likewise the cellular component of the aortic media changes, with increase in fibrocytes [14], that results in progressive thickening and stiffening of the

\section{Address for correspondence:}

Prof. Jerzy Gąsowski, Department of Internal Medicine and Gerontology, Faculty of Medicine, Jagiellonian University Medical College, ul. Śniadeckich 10 , 31-531 Kraków, Poland, e-mail: jerzy.gasowski@uj.edu.pl

Received: 29.03.2018 Accepted: 30.03.2018

Kardiologia Polska Copyright (c) Polish Cardiac Society 2018 
aorta [12-14]. This alteration has three effects of paramount importance to the pathophysiology of arterial hypertension in older patients.

First, the reduced compliance leads to less buffering of systolic pressure, which in turn causes higher values of systolic blood pressure (SBP).

Second, this means that less energy is stored and subsequently given back during diastolic elastic recoil of the aorta to the blood, resulting in lower DBP.

Third, the pressure pulse wave travels faster in stiffer aortic wall, which results in faster return of reflected wave which additionally augments systolic and lowers diastolic pressure $[15,16]$.

Another important issue in relation to ageing is gradual loss of renal function. Apart from steady decrease of glomerular filtration rate, at a rate of approximately $1 \%$ per year after the age of 35 years, the ageing kidney loses its ability to maintain adequate baseline renin production. The baseline plasma renin activity (PRA) may thus be decreased by $30 \%$ to $50 \%$. In addition, the secretion of renin in response to typical stimuli such as assumption of supine position, low sodium diet or volume depletion (as in bleeding) is also blunted [17, 18]. Earlier research by Laragh et al. [19, 20] and some more recent studies and trials $[21,22]$ suggested that antihypertensive therapy in the older patients might be guided by PRA [23, 24]. The fact that in the older patients hypertension is associated with low PRA may have important therapeutic consequences, in that the long-acting calcium channel blockers (CCB) and diuretics may be more efficacious than medications acting via blockade of the renin-angiotensin-aldosterone system.

\section{BLOOD PRESSURE LEVEL AND}

\section{CARDIOVASCULAR RISK IN OLDER PATIENTS}

The concept of harm associated with increasing level of blood pressure in older subjects was evolving over the past 90 years. Whereas still in the 1930s it was believed that higher values of especially SBP in older people were essential for the preservation of good health $[2,25]$ (hence the term 'essential hypertension' currently usually replaced by that of primary hypertension). Early results from the Framingham Heart Study indicated that in older subjects SBP rather than DBP conferred the bulk of the risk associated with hypertension [26]. This finding was independently confirmed by the MRFIT study $[27,28]$. On the other hand, a number of clinical trials performed in the 1980s concentrated on DBP alone, to the point that some of them did not even report systolic pressure values. The culmination of this concept was the seminal meta-analysis in 1990 which established the relation between level of diastolic pressure and CV risk, supported by observations that upon lowering of diastolic pressure, CV risk is decreased [29, 30]. However, it was not until 10 years later that a similar meta-analysis, performed on data of individual patients at or above the age of 60 years with systolic pressure exceeding $159 \mathrm{mmHg}$, demonstrated that greater systolic pressure is associated with increasing risk of $\mathrm{CV}$ complications, per each $10 \mathrm{mmHg}$ greater SBP there was 20\%-30\% higher risk of CV events as well as CV and all-cause mortality [6]. After adjustment for systolic pressure, lower diastolic pressure was associated with greater risk of death, underlying the importance of pulse pressure as an independent risk factor in older patients with isolated systolic hypertension. These results were in line with earlier research which demonstrated that indices of arterial stiffening, primarily pulse pressure and pulse wave velocity, are incrementally associated with elevated risk of CV events in patients with a broad spectrum of clinical settings [31], including older patients with isolated systolic hypertension, end stage kidney disease, and diabetes mellitus [31-36].

\section{THE EVIDENCE TO SUPPORT THERAPY}

Over the past quarter of century, four major placebo-controlled trials of antihypertensive therapy in older patients with isolated systolic hypertension have been published. The Systolic Hypertension in the Elderly Program (SHEP), published in 1991, included 4736 patients aged 60 years or more (57\% women) who were randomly assigned either to active regimen based on thiazide-like diuretic chlorthalidone with possible addition of atenolol, and reserpine, or matching placebos. After the average follow-up of 4.5 years actively treated patients as compared to the placebo group had $36 \%$ lower risk of all stroke, $27 \%$ reduction of the risk of coronary artery disease, and $32 \%$ reduction of the risk of combined CV events (all $p<0.01$ ) $[37,38]$. The results of this trial have to be analysed cautiously as only $1 \%$ of the original screening population was finally enrolled. In the Systolic Hypertension in Europe (Syst-Eur) trial, 4695 patients aged 60 years or more (66\% women) were randomised to receive either nitrendipine (a dihydropiridine calcium channel blocker [CCB-DHP]) based therapy with possible sequential addition of enalapril, and hydrochlorothiazide, or matching placebos. After a median follow-up of two years the trial was stopped prematurely because actively treated patients had $42 \%$ lower risk of all stroke, $26 \%$ reduction of the risk of cardiac events, and $31 \%$ reduction of the risk of CV events combined (all $p \leq 0.03$ ) [39]. The Systolic Hypertension in China (Syst-China) trial replicated the results of Syst-Eur in the Chinese population, showing, after two years of follow-up on average, $38 \%$ reduction of all stroke, 39\% reduction of CV mortality, and 39\% reduction of the risk of all-cause death (all $p \leq 0.03$ ) [40]. The results of Syst-China were at times disregarded due to the fact that instead of randomisation the protocol provided for alternate allocation of patients into the respective arms. However, as can be judged by the comparison of baseline characteristics between the two groups, such study design did not result in a systematic bias [40, 41]. Finally, the Hypertension in the Very Elderly Trial (HYVET) included 3845 patients (61\% women) at or above the age of 80 years and randomly assigned to active 
treatment based on thiazide-like diuretic indapamide with possible addition of perindopril or matching placebos [42]. After follow-up of 2.1 years the actively treated patients had $30 \%$ lower risk of stroke ( $p=0.06), 23 \%$ lower risk of CV death $(p=0.06)$, and $21 \%$ lower risk of death of all causes $(p=0.02)$. Moreover, the actively treated patients had $64 \%$ lower risk of heart failure $(p<0.001)$ [42]. However, this benefit may be attributed to a confounding factor, namely the medications used to treat hypertension in this trial came from drug classes constituting the cornerstone of medical therapy of heart failure. The interpretation of the HYVET trial is challenging because the population enrolled was extremely healthy and only about one third of the patients in this group of very old hypertensives had isolated systolic hypertension. Both facts preclude the application of the study results to the overall population of hypertensives above the age of 80 years $[43,44]$.

A number of active control studies were performed in a population of older patients with hypertension. Of these, the Losartan Intervention For Endpoint reduction in hypertension (LIFE-ISH, substudy in patients with isolated systolic hypertension and left ventricular hypertrophy) trial showed that therapy based on losartan with possible addition of hydrochlorothiazide, as compared to therapy based on atenolol with possible addition of hydrochlorothiazide, reduced the composite endpoint of stroke, myocardial infarction and CV death by $25 \%$ ( $p=0.06)$ [45]. Of particular importance is the fact that the trial did not demonstrate blood pressure difference between the two therapeutic arms [45]. The Second Australian National Blood Pressure Program (ANBP2) demonstrated $11 \%$ ( $p=0.05$ ) reduction of the relative risk of all $\mathrm{CV}$ events or death from any cause with therapy based on enalapril as compared to diuretic-based regimen. However, this marginal effect was driven by the outcome in men enrolled to the study population. No effect was seen in women [46]. Like in the LIFE-ISH trial [45], the ANBP2 did not show the between-group difference in blood pressure [46]. The SCOPE (The Study on Cognition and Prognosis in the Elderly; candesartan/hydrochlotothiazide + amiloride vs. placebos) [47], SHELL (The Systolic Hypertension in the Elderly study; lacidipine vs. chlorthalidone) [48], and INSIGHT-ISH (The International Nifedipine GITS Study: Intervention as a Goal in Hypertension Treatment, subanalysis in isolated systolic hypertension; nifedipine GITS/atenolol/enalapril vs. hydrochlorothiazide/atenonol/enalapril) [49] did not produce evidence in favour of the use of any particular medications. Overall, current evidence supports use of diuretics and long-acting CCB-DHP as the mainstay of antihypertensive therapy in older patients with isolated systolic hypertension and no other compelling indications [50-54].

Of the diuretics the preferred group would include thiazide-like compounds, as hydrochlorothiazide has been shown to be of dubious value at lower doses and potentially fraught with unfavourable side effects at blood pressure lowering doses equipotent to those of indapamide or chlorthalidone [55]. Furthermore, hydrochlorothiazide, which is a photosensitiser, has been shown to increase the risk of nonmelanoma skin cancer. In a nationwide Danish study the cumulative dose of hydrochlorothiazide of more than 50,000 mg has been associated with 29\% greater risk of basal cell carcinoma ( $p$ for trend $<0.001$ ) and $398 \%$ greater risk of squamous cell carcinoma ( $p$ for trend $<0.001$ ) [56].

Based on the results of the Anglo-Scandinavian Cardiac Outcomes Trial (ASCOT), where regimen based on combination of long-acting CCB-DHP amlodipine and angiotensin-converting enzyme inhibitor (ACEI) perindopril and was superior to combination of $\beta$-blocker atenolol and thiazide diuretic bendroflumethiazide [57], the use of the combination of ACEI and CCB-DHP has been advocated, including the older patients $[57,58]$. Indeed the ASCOT results indicated that the benefit was present independent of whether the patients were younger than 60 years or older [57]. However, the use of atenolol as a comparator has been widely criticised [59-61], as the medication is believed to confer little or no benefit in hypertensive subjects [62, 63]. Moreover, in older subjects atenolol may even increase central blood pressure, as was demonstrated in the CAFE study [64].

Another issue is the use of alpha-adrenolytic medications such as doxazosin, which may be tempting especially in older male patients with hypertension and coexisting benign prostatic hyperplasia. Since the publication of an initial report of the Antihypertensive and Lipid-Lowering Treatment to Prevent Heart Attack Trial (ALLHAT) $[65,66]$, doxazosin has been moved to the third or even fourth line of antihypertensive regimens, especially in the elderly [54]. However, the closer scrutiny of the ALLHAT report reveals possibility of significant bias [65]. First, during the run-in period of the trial patients were to undergo a wash-out period, during which previous antihypertensive therapy was discontinued. Then, the patients were randomly assigned to one of four arms, including chlorthalidone and doxazosin. The doxazosin arm was discontinued prematurely because significantly more patients had episodes of heart failure and CV disease. However, neither the primary outcome of coronary heart disease, nor all-cause mortality differed between the doxazosine and chlorthalidone groups [65]. Of note, patients in the doxazosin arm during the entire trial had systolic pressure higher by 2 to $3 \mathrm{mmHg}$ than individuals assigned to chlorthalidone; the difference was likely to account for a $5 \%$ to $9 \%$ difference in outcome [6]. Clearly, doxazosin is neither first nor second line antihypertensive medication in the older patients, especially in monotherapy of patients with or at high risk of developing heart failure. Doxazosin must be used with caution and should best be avoided in patients with orthostatic hypotension. However, in patients in whom escalation of antihypertensive regimen is needed, especially those who would not tolerate 
anti-aldosterone compounds, or in male subjects with coexisting benign prostatic hyperplasia, doxazosin may still be useful, although to limit the risk of side effects the long-acting formulation should be preferred [54].

An all-important question of the cut-off for the definition of hypertension and the initiation of antihypertensive therapy has recently been refueled with the publication of the results of the SPRINT trial results and SPRINT-AGED subanalysis [67]. SPRINT was a randomised trial evaluating the intensive $(<120 \mathrm{mmHg}$ ) or standard (135-139 mmHg) goal of antihypertensive therapy. The study, which was carried according to the PROBE (prospective, randomised, open-label, blinded endpoint assessment) design [68], included hypertensive patients aged over 50 years with SBP values of between 130 and $180 \mathrm{mmHg}$. The patients had to be free from diabetes mellitus but otherwise they had to be burdened by high CV risk profile [67]. The main report described the data on the initial cohort of 9361 patients. Overall, the trial demonstrated significant reduction of relative risk of sustaining the primary composite endpoint of non-fatal acute coronary syndrome (including non-fatal myocardial infarction), non-fatal stroke, non-fatal exacerbation of heart failure and CV death, by $25 \%$ $(p<0.001)$ and all-cause death by $27 \%(p=0.003)$ [67]. The subgroup analysis in older patients showed that the relative risk of composite primary endpoint as described above, was reduced by $34 \%(p=0.001)$ and death of all causes by $33 \%$ $(p=0.009)$ [69]. In the entire study group, these benefits were achieved at the statistically significant cost of an increase in the risk of hypotension, acute renal failure, and hyponatraemia of the magnitude similar to that of the reported benefit [67, 70]. In the subgroup of patients older than 75 years, there was a marginally non-significant trend for a greater relative risk of hypotension by $71 \%$ and syncope by $23 \%$ [69].

The interpretation of both reports of the SPRINT trial poses several problems. First, the blood pressures reported by the authors were not standard office measurements. Instead, blood pressures were measured with an automated oscyllometric device with the patient left at his or her leisure without presence of a healthcare professional. A number of studies demonstrated that the unattended blood pressure measurements may be associated with 9.0-15/6.0-8.0 mmHg lower $\mathrm{SBP} / \mathrm{DBP}$ values as compared to standard office measurements [71-73]. This led Filipovský et al. [73] to the conclusion that the level of unattended blood pressure corresponding to office blood pressure of 140/90 mmHg should be 125/82 mmHg, systolic and diastolic pressure, respectively.

All of the recently performed large-scale clinical trials used measurement of blood pressure in an attended fashion. This drawback makes the comparisons of the outcome of these trials and the SPRINT feasible only when the adjustment for the difference in blood pressure using different methods is taken into consideration [74]. However, this is not where the interpretational problems of the SPRINT trial stop. In order to separate the groups on the basis of achieved blood pressure, the provision had been made in the protocol to the effect that a patient randomised to standard therapy with the average SBP of $130 \mathrm{mmHg}$ or less during a single visit or with the average SBP of $135 \mathrm{mmHg}$ or less during two consecutive visits should have his or her medications tapered down in order to maintain the SBP between 135 and $139 \mathrm{mmHg}$ [67, 75]. According to data presented in the main report of the trial, at the initial visit alone, there were about 15,000 such persons [67]. The report on the participants aged 75 years or more does not cite the blood pressure strata, however some information may be extrapolated based on the similar behaviour of systolic pressure in the standard treatment group in both the principal and the $75+$ reports of the SPRINT trial $[67,69]$. The subgroup analysis according to initial SBP in the entire study group demonstrated that only in the patients from the lowest unattended SBP stratum $(<132 \mathrm{mmHg})$ a statistically significant reduction of the risk of endpoints was achieved. This finding may in part reflect the fact that this group included the bulk of patients who had their medications tapered down, and that patients from this group would have achieved adequate control of SBP if office values had been substituted for unattended measurements. The closer scrutiny of the blood pressure graphs leads to the conclusion that in the strict blood pressure control group SBP averaged $129.1 \mathrm{mmHg}$ at one month and further fell by $2.5 \mathrm{mmHg}$ by six months and by additional $0.2 \mathrm{mmHg}$ by one year, when it averaged $126.4 \mathrm{mmHg}$. On the other hand, SBP in the standard treatment group at one month averaged $131.3 \mathrm{mmHg}$ and increased by the time of six-month visit by $0.6 \mathrm{mmHg}$ and by further $0.7 \mathrm{mmHg}$ by one year into the trial, averaging $132.6 \mathrm{mmHg}$ (visual inspection of Figure 2 from reference [67]). Based on the previous research one can assume that the thus produced $6.2 \mathrm{mmHg}$ between-group difference in SBP could have been translated into $16 \%$ greater relative risk of all CV events in the standard treatment group compared with the strict blood pressure control group [6]. When corrected according to data published by Filipovský et al. [73], these one year unattended SBP readings would be $141.4 \mathrm{mmHg}$ in the strict control group and $147.6 \mathrm{mmHg}$ in the standard control group. This observation is somewhat in line with the largely negative results of the Japanese Trial to Assess Optimal Systolic Blood Pressure in Elderly Hypertensive patients (JATOS), in which the reduction of SBP on average to below $140 \mathrm{mmHg}$ did not offer more benefit in older Japanese patients as compared to less strict blood pressure control to below $160 \mathrm{mmHg}$ [76].

After the publication of the SPRINT results, a number of meta-analyses, which included the summary data of this trial appeared. These meta-analyses advocated that SBP should be universally reduced to below $130 \mathrm{mmHg}$ [77-79]. In these reports the sheer weight of the SPRINT group seemed to draw the results towards lower blood pressure goals to be achieved with antihypertensive therapy. However, due to the 
aforementioned problems concerning interpretation of the SPRINT trial, despite the sincerity of the effort on the part of the authors of the cited meta-analyses and the investigators of the SPRINT trial, the conclusions to the effect that all our hypertensive patients, irrespective of age, should have their office SBPs reduced to below $130 \mathrm{mmHg}$ seem rather far-fetched. In fact, if data by Lund-Johansen et al. [71], Mancia et al. [72] and recently Filipovský et al. [73] are correct, the SPRINT was a trial assessing the standard control of blood pressure versus no control.

The possible practical answer to the question of the evidence supporting the particular level of SBP, when measured by a physician or a nurse in an office setting, may be supported by the two post-hoc analyses of the INternational VErapamil SR-Trandolapril STudy (INVEST) [80, 81]. An analysis published by Denardo et al. [80] demonstrated that the achieved, on-treatment, SBP at which risk is lowest differs according to patients' age. Whereas, SBP in younger individuals can be safely decreased to below $140 \mathrm{mmHg}$ and no harm is observed at as low values as $120-130 \mathrm{mmHg}$, in patients older than 70 years of age the lowest risk is noted with the SBP around $140 \mathrm{mmHg}$ and when the achieved values decrease to below 135-140 $\mathrm{mmHg}$, the risk starts increasing [80]. Of note, the $U$-shaped relation between achieved blood pressure and CV risk was present for both SBP and DBP [80]. Elgendy et al. [81] brought these results a step further. In a report published in 2016 they demonstrated that after maximum of 11 years of extended follow-up for fatal events, the lowest risk for older patients was associated with SBP of between 130 and $140 \mathrm{mmHg}$, with slightly less favourable results for SBP below $130 \mathrm{mmHg}$ and between 140 and $150 \mathrm{mmHg}$, and much worse outcomes in patients with SBP exceeding $150 \mathrm{mmHg}[70,81]$. However, the analysis by Elgendy et al. [81] is not free of potential flaws, as the blood pressure values on which they base their estimates extended only to 2.7 years of average follow-up.

A recent meta-analysis lent support to lowering of SBP in older hypertensive patients to values below $140 \mathrm{mmHg}$ [82]. The authors demonstrated that such therapy reduces major adverse CV events by $29 \%$ ( $p<0.001)$, all-cause mortality by $33 \%(p=0.04)$, and heart failure by $37 \%(p=0.04)$, however this may come at a cost of polypharmacy, and increased risk of such complications as acute kidney injury, hypotension, and syncope [82].

Further evidence came with the publication of data from the Heart Outcomes Prevention Evaluation (HOPE)-3 trial, which indicated that lowering of SBP to less than $130 \mathrm{mmHg}$ with active antihypertensive therapy in intermediate risk subjects, with a mean age of 65.7 and no CV disease, with an exception for individuals with initial SBP values exceeding $143.5 \mathrm{mmHg}$, did not confer CV benefit [83, 84]. The benefit in these individuals was restricted to the use of rosuvastatin with a marginally greater benefit associated with co-administration of candesartan and hydrochlorothiazide [84].

\section{CONCLUSIONS}

The initiation of antihypertensive therapy or its up-titration should be performed carefully in older patients. One should remember that the population of older patients include on one hand generally healthy, biologically younger and fitter individuals, and on the other hand, frail individuals with high degree of comorbidity and polypharmacy. Whereas the former can be approached in a manner in many respects similar to our approaches to younger patients, the latter needs to be addressed more specifically [44]. The importance of the approaches taking into consideration patient's age is wide-ranging. From the issues concerning compliance [85], through potential complications of therapy such as hyponatraemia, hypotension and falls, to a possible inadvertent increase in the risk of $\mathrm{CV}$ events in cases where achieved blood pressure would be inappropriately high or inappropriately low [70, 86].

Conflict of interest: J. Gąsowski has consultant or advisory relationships with Astellas, Servier, and Pfizer. K. Piotrowicz has nothing to disclose in relation to the present work. F.H. Messerli has consultant or advisory relationships with Daiichi-Sankyo, Pfizer, Abbott, Servier, Medtronic, WebMD, Ipca, American College of Cardiology, Menarini, Relypsa, and the University of Utah.

\section{References}

1. Vasan RS, Beiser A, Seshadri S, et al. Residual lifetime risk for developing hypertension in middle-aged women and men: The Framingham Heart Study. JAMA. 2002; 287(8): 1003-1010, indexed in Pubmed: 11866648.

2. Messerli FH, Williams B, Ritz E. Essential hypertension. Lancet. 2007; 370(9587): 591-603, doi: 10.1016/S0140-6736(07)61299-9, indexed in Pubmed:17707755.

3. Lewington S, Clarke R, Qizilbash N, et al. Age-specific relevance of usual blood pressure to vascular mortality: a meta-analysis of individual data for one million adults in 61 prospective studies. Lancet. 2002; 360(9349): 1903-1913, indexed in Pubmed: 12493255 .

4. Li W, Jin C, Vaidya A, et al. Blood pressure trajectories and the risk of intracerebral hemorrhage and cerebral infarction: a prospective study. Hypertension. 2017; 70(3): 508-514, doi: 10.1161/HYPERTENSIONAHA.117.09479, indexed in Pubmed: 28716992.

5. Petruski-Ivleva N, Viera AJ, Shimbo D, et al. Longitudinal patterns of change in systolic blood pressure and incidence of cardiovascular disease: the atherosclerosis risk in communities study. Hypertension. 2016; 67(6): 1150-1156, doi: 10.1161/HYPERTENSIONAHA.115.06769, indexed in Pubmed:27045024.

6. Staessen JA, Gasowski J, Wang JG, et al. Risks of untreated and treated isolated systolic hypertension in the elderly: meta-analysis of outcome trials. Lancet. 2000; 355(9207): 865-872, indexed in Pubmed: 10752701.

7. Ettehad D, Emdin CA, Kiran A, et al. Blood pressure lowering for prevention of cardiovascular disease and death: a systematic review and meta-analysis. Lancet. 2016; 387(10022): 957-967, doi: 10.1016/S0140-6736(15)01225-8, indexed in Pubmed: 26724178. 
8. Katsanos A, Filippatou A, Manios E, et al. Blood pressure reduction and secondary stroke preventionnovelty and significance. Hypertension. 2016; 69(1): 171-179, doi: 10.1161/hypertensionaha.116.08485.

9. Li JZ, Eagle KA, Vaishnava P. Hypertensive and acute aortic syndromes. Cardiol Clin. 2013; 31(4): 493-501, vii, doi: 10.1016/j. ccl.2013.07.011, indexed in Pubmed: 24188216.

10. Brunström M, Carlberg B. Association of blood pressure lowering with mortality and cardiovascular disease across blood pressure levels: a systematic review and meta-analysis. JAMA Intern Med. 2018; 178(1): 28-36, doi: 10.1001/jamainternmed.2017.6015, indexed in Pubmed: 29131895.

11. Harvey A, Montezano AC, Touyz RM. Vascular biology of ageing-Implications in hypertension. J Mol Cell Cardiol. 2015 83: 112-121, doi:10.1016/j.yjmcc.2015.04.011, indexed in Pubmed: 25896391.

12. Laurent S, Tropeano AI, Lillo-Lelouet A, et al. Local pulse pressure is a major determinant of large artery remodelling. Clin Exp Pharmacol Physiol. 2001; 28(12): 1011-1014, indexed in Pubmed: 11903305.

13. Yao Q, Hayman DM, Dai Q, et al. Alterations of pulse pressure stimulate arterial wall matrix remodeling. J Biomech Eng. 2009; 131(10): 101011, doi:10.1115/1.3202785, indexed in Pubmed: 19831481.

14. Wu J, Montaniel KR, Saleh MA, et al. Origin of Matrix-Producing Cells That Contribute to Aortic Fibrosis in Hypertension. Hypertension. 2016; 67(2): 461-468, doi: 10.1161/HYPERTENSIONAHA.115.06123, indexed in Pubmed: 26693821.

15. Xu X, Wang B, Ren C, et al. Age-related Impairment of Vascular Structure and Functions. Aging Dis. 2017; 8(5): 590-610, doi: 10.14336/AD.2017.0430, indexed in Pubmed: 28966804.

16. Pagoulatou S, Stergiopulos N. Evolution of aortic pressure during normal ageing: A model-based study. PLoS One. 2017; 12(7): 1-14, doi:10.1371/journal.pone.0182173, indexed in Pubmed: 28753657.

17. Belmin J, Lévy BI, Michel JB. Changes in the renin-angiotensin-aldosterone axis in later life. Drugs Aging. 1994; 5(5): 391-400, indexed in Pubmed:7833591.

18. Bolignano D, Mattace-Raso F, Sijbrands EJG, et al. The aging kidney revisited: a systematic review. Ageing Res Rev. 2014; 14: 65-80, doi:10.1016/j.arr.2014.02.003, indexed in Pubmed: 24548926 .

19. Laragh JH, Letcher RL, Pickering TG. Renin profiling for diagnosis and treatment of hypertension. JAMA. 1979; 241(2): 151-156, indexed in Pubmed:31492.

20. Laragh JH. The renin system and future trends in management of high blood pressure. Clin Exp Hypertens. 1980; 2(3-4): 525-552, indexed in Pubmed:6253242.

21. Alderman $\mathrm{MH}$, Cohen HW, Sealey JE, et al. Pressor responses to antihypertensive drug types. Am J Hypertens. 2010; 23(9): 1031 1037, doi:10.1038/ajh.2010.114, indexed in Pubmed: 20725055.

22. Gonzalez MC, Cohen HW, Sealey JE, et al. Enduring direct association of baseline plasma renin activity with all-cause and cardiovascular mortality in hypertensive patients. Am J Hypertens. 2011; 24(11): 1181-1186, doi: 10.1038/ajh.2011.172, indexed in Pubmed: 21938071.

23. Egan BM, Basile JN, Rehman SU, et al. Plasma Renin test-guided drug treatment algorithm for correcting patients with treated but uncontrolled hypertension: a randomized controlled trial. Am J Hypertens. 2009; 22(7): 792-801, doi: 10.1038/ajh.2009.63, indexed in Pubmed: 19373213.

24. Sim JJ, Bhandari SK, Shi J, et al. Plasma renin activity (PRA) levels and antihypertensive drug use in a large healthcare system. Am J Hypertens. 2012; 25(3): 379-388, doi: 10.1038/ajh.2011.216, indexed in Pubmed: 22158065.

25. Messerli FH, Sundgaard-Riise K, Ventura HO, et al. Essential hypertension in the elderly: haemodynamics, intravascular volume, plasma renin activity, and circulating catecholamine levels. Lancet. 1983; 2(8357): 983-986, indexed in Pubmed: 6138591.

26. Kannel WB, Gordon T, Schwartz MJ. Systolic versus diastolic blood pressure and risk of coronary heart disease. The Framingham study. Am J Cardiol. 1971; 27(4): 335-346, indexed in Pubmed: 5572576.

27. Flack JM, Neaton J, Grimm R, et al. Blood pressure and mortality among men with prior myocardial infarction. Multiple Risk Factor Intervention Trial Research Group. Circulation. 1995; 92(9): 2437-2445, indexed in Pubmed: 7586343.

28. Leonetti G, Cuspidi C, Facchini M, et al. Is systolic pressure a better target for antihypertensive treatment than diastolic pressure? J Hypertens Suppl. 2000; 18(3): S13-S20, indexed in Pubmed: 10952083.

29. MacMahon S, Peto R, Cutler J, et al. Blood pressure, stroke, and coronary heart disease. Part 1. Prolonged differences in blood pressure: prospective observational studies corrected for the regression dilution bias. Lancet. 1990; 335(8692): 765-774, indexed in Pubmed: 1969518.

30. Collins R, Peto R, MacMahon S, et al. Blood pressure, stroke, and coronary heart disease. Part 2, Short-term reductions in blood pressure: overview of randomised drug trials in their epidemiological context. Lancet. 1990; 335(8693): 827-838, indexed in Pubmed: 1969567.

31. Vlachopoulos C, Aznaouridis K, Stefanadis C. Prediction of cardiovascular events and all-cause mortality with arterial stiffness: a systematic review and meta-analysis. J Am Coll Cardiol. 2010; 55(13): 1318-1327, doi: 10.1016/j.jacc.2009.10.061, indexed in Pubmed: 20338492.

32. Avolio A, Kim MiOk, Adji A, et al. Cerebral Haemodynamics: Effects of Systemic Arterial Pulsatile Function and Hypertension. Curr Hypertens Rep. 2018; 20(3): 20, doi: 10.1007/s11906-0180822-x, indexed in Pubmed: 29556793.

33. Mattace-Raso FUS, van der Cammen TJM, Hofman A, et al. Arterial stiffness and risk of coronary heart disease and stroke: the Rotterdam Study. Circulation. 2006; 113(5): 657-663, doi: 10.1161/CIRCULATIONAHA.105.555235, indexed in Pubmed: 16461838.

34. Sutton-Tyrrell K, Najjar SS, Boudreau RM, et al. Elevated aortic pulse wave velocity, a marker of arterial stiffness, predicts cardiovascular events in well-functioning older adults. Circulation. 2005; 111(25): 3384-3390, doi: 10.1161/CIRCULATIONAHA.104.483628, indexed in Pubmed: 15967850.

35. Bangalore S, Messerli FH, Franklin SS, et al. Pulse pressure and risk of cardiovascular outcomes in patients with hypertension and coronary artery disease: an INternational VErapamil SR-trandolapril STudy (INVEST) analysis. Eur Heart J. 2009; 30(11): 1395-1401, doi: 10.1093/eurheartj/ehp109, indexed in Pubmed: 19351690.

36. Smulyan H, Lieber A, Safar ME. Hypertension, diabetes type II, and their association: role of arterial stiffness. Am J Hypertens. 2016; 29(1): 5-13, doi:10.1093/ajh/hpv107, indexed in Pubmed: 26156872

37. Staessen J, Fagard R, Amery A. Isolated systolic hypertension in the elderly: implications of Systolic Hypertension in the Elderly Program (SHEP) for clinical practice and for the ongoing trials. J Hum Hypertens. 1991; 5(6): 469-474, indexed in Pubmed: 1791605.

38. Prevention of stroke by antihypertensive drug treatment in older persons with isolated systolic hypertension. Final results of the Systolic Hypertension in the Elderly Program (SHEP). SHEP Cooperative Research Group. JAMA. 1991; 265(24): 3255-3264, indexed in Pubmed: 2046107.

39. Staessen JA, Fagard R, Thijs L, et al. Randomised double-blind comparison of placebo and active treatment for older patients with isolated systolic hypertension. The Systolic Hypertension in Europe (Syst-Eur) Trial Investigators. Lancet. 1997; 350(9080): 757-764, indexed in Pubmed: 9297994. 
40. Liu L, Wang JG, Gong L, et al. Comparison of active treatment and placebo in older Chinese patients with isolated systolic hypertension. Systolic Hypertension in China (Syst-China) Collaborative Group. J Hypertens. 1998; 16(12 Pt 1): 1823-1829, indexed in Pubmed: 9869017

41. Wang JG, Staessen JA, Gong L, et al. Chinese trial on isolated systolic hypertension in the elderly. Systolic Hypertension in China (Syst-China) Collaborative Group. Arch Intern Med. 2000; 160(2): 211-220, doi: 10.1001/archinte.160.2.211.

42. Beckett N, Peters R, Fletcher A, et al. Treatment of Hypertension in Patients 80 Years of Age or Older. N Engl J Med. 2008; 358(18): 1887-1898, doi:10.1056/nejmoa0801369.

43. Messerli FH, Sulicka J, Gryglewska B. Treatment of hypertension in the elderly. N Engl J Med. 2008; 359(9): 971-974, doi: 10.1056/nejmc081224.

44. Benetos A, Rossignol P, Cherubini A, et al. Polypharmacy in the aging patient: management of hypertension in octogenarians. JAMA. 2015; 314(2): 170-180, doi: 10.1001/jama.2015.7517, indexed in Pubmed: 26172896.

45. Kjeldsen S, Dahlöf B, Devereux R, et al. Effects of losartan on cardiovascular morbidity and mortality in patients with isolated systolic hypertension and left ventricular hypertrophy. A Losartan Intervention for Endpoint Reduction (LIFE) substudy. JAMA. 2002; 288(12): 1491-1498, doi:10.1001/jama.288.12.1491.

46. Wing LMH, Reid CM, Ryan P, et al. A comparison of outcomes with angiotensin-converting--enzyme inhibitors and diuretics for hypertension in the elderly. N Engl J Med. 2003; 348(7): 583-592, doi: 10.1056/NEJMoa021716, indexed in Pubmed: 12584366.

47. Gayet JL, Lithell H, Hansson L, et al. The Study on Cognition and Prognosis in the Elderly (SCOPE): principal results of a randomized double-blind intervention trial. J Hypertens. 2003; 21(5): 875-886, doi: 10.1097/01.hjh.0000059028.82022.89, indexed in Pubmed: 12714861.

48. Malacco E, Mancia G, Rappelli A, et al. Treatment of isolated systolic hypertension: the SHELL study results. Blood Press. 2003; 12(3): 160-167, indexed in Pubmed: 12875478.

49. Mancia G, Ruilope L, Palmer C, et al. Effects of nifedipine GITS and diuretics in isolated systolic hypertension: a subanalysis of the INSIGHT study. Blood Press. 2004; 13(5): 310-315, doi: 10.1080/08037050410022954, indexed in Pubmed: 15545155 .

50. Rimoldi SF, Messerli FH, Chavez P, et al. Efficacy and safety of calcium channel blocker/diuretics combination therapy in hypertensive patients: a meta-analysis. J Clin Hypertens (Greenwich). 2015; 17(3): 193-199, doi: 10.1111/jch.12462, indexed in Pubmed: 25556777.

51. Whelton PK, Carey RM, Aronow WS, et al. 2017 Guideline for the Prevention, Detection, Evaluation, and Management of High Blood Pressure in Adults A Report of the American College of Cardiology / American Heart Association T. J Am Coll Cardiol. 2017: 283.

52. James PA, Oparil S, Carter BL, et al. 2014 evidence-based guideline for the management of high blood pressure in adults: report from the panel members appointed to the Eighth Joint National Committee (JNC 8). JAMA. 2014; 311(5): 507-520, doi: 10.1001/jama.2013.284427, indexed in Pubmed: 24352797.

53. Mancia G, Fagard R, Narkiewicz K, et al. 2013 ESH/ESC guidelines for the management of arterial hypertension: the Task Force for the Management of Arterial Hypertension of the European Society of Hypertension (ESH) and of the European Society of Cardiology (ESC). Eur Heart J. 2013; 34(28): 2159-2219, doi: 10.1093/eurheartj/eht151, indexed in Pubmed: 23771844.

54. Tykarski A, Narkiewicz K, Gaciong Z, et al. Zasady postępowania w nadciśnieniu tętniczym - 2015 rok Wytyczne Polskiego Towarzystwa Nadciśnienia Tętniczego. [2015 guidelines for the management of hypertension. Recommendations of the Polish Society of Hypertension]. Nadciśnienie Tętnicze w Praktyce. $2015 ; 1(1): 1-70$
55. Messerli FH, Bangalore S. Half a century of hydrochlorothiazide: facts, fads, fiction, and follies. Am J Med. 2011; 124(10): 896-899, doi:10.1016/j.amjmed.2011.05.009, indexed in Pubmed: 21962309

56. Pedersen SA, Gaist D, Schmidt SA, et al. Hydrochlorothiazide use and risk of nonmelanoma skin cancer: A nationwide case-control study from Denmark. J Am Acad Dermatol. 2018; 78(4): 673-681.e9, doi: 10.1016/j.jaad.2017.11.042, indexed in Pubmed: 29217346.

57. Dahlöf B, Sever PS, Poulter NR, et al. Prevention of cardiovascular events with an antihypertensive regimen of amlodipine adding perindopril as required versus atenolol adding bendroflumethiazide as required, in the Anglo-Scandinavian Cardiac Outcomes Trial-Blood Pressure Lowering Arm (ASCOT-BPLA): a multicentre randomised controlled trial. Lancet. 2005; 366(9489): 895-906, doi: 10.1016/S0140-6736(05)67185-1, indexed in Pubmed:16154016.

58. Lionakis N, Mendrinos D, Sanidas E, et al. Hypertension in the elderly. World J Cardiol. 2012; 4(5): 135-147, doi: 10.4330/wjc. v4.i5.135, indexed in Pubmed: 22655162.

59. Zarnke KB. Amlodipine plus perindopril was better than atenolol plus bendroflumethiazide for reducing complications in hypertension. Evid-Based Med. 2006; 11(2): 42-42, doi: 10.1136/ebm.11.2.42.

60. Fuchs F, Gus M, Ribeiro J. ASCOT-BPLA. Lancet. 2006; 367(9506): 205-206. Author reply 207-208, doi: 10.1016/s01406736(06)68022-7.

61. Donzelli A, Malliani A. ASCOT-BPLA. Lancet. 2006; 367(9506): 205-206, doi: 10.1016/s0140-6736(06)68023-9.

62. Carlberg B, Samuelsson O, Lindholm LH. Atenolol in hypertension: is it a wise choice? Lancet. 2004; 364(9446): 1684-1689, doi: 10.1016/S0140-6736(04)17355-8, indexed in Pubmed: 15530629.

63. Wiysonge C, Bradley H, Volmink J, et al. Beta-blockers for hypertension. Cochrane Database Syst Rev. 2017; 1: CD002003, doi:10.1002/14651858.cd002003.pub5.

64. Williams B, Lacy PS, Thom SM, et al. Differential impact of blood pressure-lowering drugs on central aortic pressure and clinical outcomes: principal results of the Conduit Artery Function Evaluation (CAFE) study. Circulation. 2006; 113(9): 1213-1225, doi: 10.1161/CIRCULATIONAHA.105.595496, indexed in Pubmed: 16476843

65. Major cardiovascular events in hypertensive patients randomized to doxazosin vs chlorthalidone: the antihypertensive and lipid-lowering treatment to prevent heart attack trial (ALLHAT). ALLHAT Collaborative Research Group. JAMA. 2000; 283(15): 1967-1975, indexed in Pubmed: 10789664.

66. Antihypertensive and Lipid-Lowering Treatment to Prevent Heart Attack Trial Collaborative Research Group. Diuretic versus alpha-blocker as first-step antihypertensive therapy: final results from the Antihypertensive and Lipid-Lowering Treatment to Prevent Heart Attack Trial (ALLHAT). Hypertension. 2003; 42(3): 239-246, doi: 10.1161/01.HYP.0000086521.95630.5A, indexed in Pubmed: 12925554.

67. Wright JT, Williamson JD, Whelton PK, et al. A randomized trial of intensive versus standard blood-pressure control. N Engl J Med. 2015; 373(22): 2103-2116, doi: 10.1056/NEJMoa1511939, indexed in Pubmed: 26551272.

68. Hansson L, Hedner T, Dahlöf B. Prospective randomized open blinded end-point (PROBE) study. A novel design for intervention trials. Prospective Randomized Open Blinded End-Point. Blood Press. 1992; 1(2): 113-119, indexed in Pubmed: 1366259.

69. Williamson JD, Supiano MA, Applegate WB, et al. Intensive vs standard blood pressure control and cardiovascular disease outcomes in adults aged $\geq 75$ years: a randomized clinical trial. JAMA. 2016; 315(24): 2673-2682, doi: 10.1001/jama.2016.7050, indexed in Pubmed: 27195814. 
70. Gąsowski J, Piotrowicz K. Blood pressure target: high time that we finally agreed what is healthy. Hypertension. 2016; 68(5): 1103-1105, doi:10.1161/HYPERTENSIONAHA.116.07940, indexed in Pubmed: 27620398.

71. Lund-Johansen P, Omvik P, Lund-Johansen P, et al. Central haemodynamics in essential hypertension. Acta Med Scand Suppl. 1977; 606(4): 35-42, indexed in Pubmed: 268932.

72. Mancia G, Parati G, Pomidossi G, et al. Alerting reaction and rise in blood pressure during measurement by physician and nurse. Hypertension. 1987; 9(2): 209-215, indexed in Pubmed: 3818018.

73. Filipovský J, Seidlerová J, Kratochvíl Z, et al. Automated compared to manual office blood pressure and to home blood pressure in hypertensive patients. Blood Press. 2016; 25(4): 228-234, doi: 10.3109/08037051.2015.1134086, indexed in Pubmed: 26852625.

74. Kjeldsen SE, Lund-Johansen P, Nilsson PM, et al. Unattended blood pressure measurements in the systolic blood pressure intervention trial: implications for entry and achieved blood pressure values compared with other trials. Hypertension. 2016; 67(5): 808-812, doi:10.1161/HYPERTENSIONAHA.116.07257, indexed in Pubmed: 27001295.

75. Systolic Blood Pressure Intervention Trial (SPRINT) protocol. Nov 1. 2012 [Internet]. https://www.sprinttrial.org/public/Protocol_Current.pdf.

76. JATOS Study Group. Principal results of the Japanese trial to assess optimal systolic blood pressure in elderly hypertensive patients (JATOS). Hypertens Res. 2008; 31(12): 2115-2127, doi: 10.1291/hypres.31.2115, indexed in Pubmed: 19139601.

77. Ettehad D, Emdin CA, Kiran A, et al. Blood pressure lowering for prevention of cardiovascular disease and death: a systematic review and meta-analysis. Lancet. 2016; 387(10022): 957-967, doi: 10.1016/S0140-6736(15)01225-8, indexed in Pubmed: 26724178.

78. Bangalore S, Toklu B, Gianos E, et al. Optimal systolic blood pressure target after SPRINT: insights from a network meta-analysis of randomized trials. Am J Med. 2017; 130(6): 707-719.e8, doi: 10.1016/j.amjmed.2017.01.004, indexed in Pubmed: 28109971.

79. Kjeldsen SE, Hedner T, Narkiewicz K. HOPE-3, SPRINT, VALUE and a meta-analysis of trials in patients with diabetes support treatment of hypertension to a target below $140 \mathrm{mmHg}$. Blood Press. 2016; 25(3): 131-132, doi: 10.1080/08037051.2016.1182 857, indexed in Pubmed: 27160151.

80. Denardo SJ, Gong Y, Nichols WW, et al. Blood pressure and outcomes in very old hypertensive coronary artery disease patients: an INVEST substudy. Am J Med. 2010; 123(8): 719-726, doi: 10.1016/j. amjmed.2010.02.014, indexed in Pubmed: 20670726.

81. Elgendy IY, Bavry AA, Gong Y, et al. Long-Term mortality in hypertensive patients with coronary artery disease: results from the US cohort of the international verapamil (SR)/trandolapril study. Hypertension. 2016; 68(5): 1110-1114, doi: 10.1161/HYPERTENSIONAHA.116.07854, indexed in Pubmed: 27620390.

82. Bavishi C, Bangalore S, Messerli FH. Outcomes of Intensive Blood Pressure Lowering in Older Hypertensive Patients. J Am Coll Cardiol. 2017; 69(5): 486-493, doi: 10.1016/j.jacc.2016.10.077, indexed in Pubmed: 28153104.

83. Yusuf S, Bosch J, Dagenais G, et al. Cholesterol lowering in intermediate-risk persons without cardiovascular disease. New Engl J Med. 2016; 374(21): 2021-2031, doi: 10.1056/nejmoa1600176.

84. Yusuf S, Lonn E, Pais P, et al. Blood-Pressure and cholesterol lowering in persons without cardiovascular disease. New Engl J Med. 2016; 374(21): 2032-2043, doi: 10.1056/nejmoa1600177.

85. Piotrowicz K, Prejbisz A, Klocek M, et al. Subclinical mood and cognition impairments and blood pressure control in a large cohort of elderly hypertensives. J Am Med Dir Assoc. 2016; 17(9): 864.e17-864.e22, doi: 10.1016/j.jamda.2016.06.021, indexed in Pubmed: 27502451.

86. Gasowski J, Piotrowicz K, Grodzicki T. Safety vs efficacy of lowering blood pressure. JAMA Cardiol. 2017; 2(12): 1398, doi:10.1001/jamacardio.2017.3537, indexed in Pubmed: 28979979

Cite this article as: Gąsowski J, Piotrowicz K, Messerli FH. Arterial hypertension after age 65: from epidemiology and pathophysiology to therapy. Do we know where we stand? Kardiol Pol. 2018; 76(4): 723-730, doi: 10.5603/KP.2018.0075. 